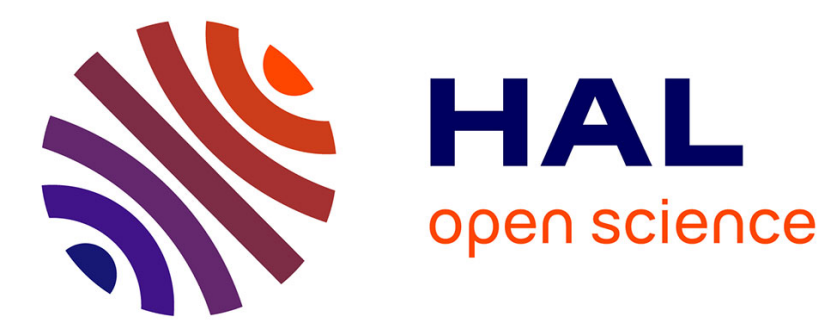

\title{
Building hygrothermal modeling by nodal method
}

Farah Gabsi, Frédéric Hamelin, Nathalie Sauer

\section{To cite this version:}

Farah Gabsi, Frédéric Hamelin, Nathalie Sauer. Building hygrothermal modeling by nodal method. International Conference on Innovative Smart Grid Technologies, ISGT Asia 2018, May 2018, Singapour, Singapore. hal-01825323

\section{HAL Id: hal-01825323 \\ https://hal.science/hal-01825323}

Submitted on 28 Jun 2018

HAL is a multi-disciplinary open access archive for the deposit and dissemination of scientific research documents, whether they are published or not. The documents may come from teaching and research institutions in France or abroad, or from public or private research centers.
L'archive ouverte pluridisciplinaire HAL, est destinée au dépôt et à la diffusion de documents scientifiques de niveau recherche, publiés ou non, émanant des établissements d'enseignement et de recherche français ou étrangers, des laboratoires publics ou privés. 


\section{Building hygrothermal modeling by nodal method}

\author{
Farah Gabsi \\ Université de Lorraine \\ CNRS, CRAN, F-54000 Nancy, France \\ LGIPM, F-57000 Metz, France \\ Farah.Gabsi@univ-lorraine.fr
}

\author{
Frédéric Hamelin \\ Université de Lorraine \\ CNRS, CRAN, F-54000 Nancy, France \\ Frederic.Hamelin@univ-lorraine.fr
}

\author{
Nathalie Sauer \\ Université de Lorraine \\ LGIPM, F-57000 Metz, France \\ Nathalie.Sauer@univ-lorraine.fr
}

\begin{abstract}
This article deals with the problem of modeling a multi-zone office building to ensure its hygrothermal comfort. An analysis of the hygrothermal behavior is carried out using a nodal method based on the SimscapeTM library in MATLAB/Simulink ${ }^{\circledR}$ environment. The application target is the "Eco-Safe" platform (CRAN Nancy, France) that fits in a global context of smart home [1].

Index Terms-buildings, hygrothermal modeling, thermal comfort, nodal analysis.
\end{abstract}

\section{INTRODUCTION}

The park of existing buildings in France has 2/3 of dwellings built before 1975. The renewal rate of this park is less than $1 \%$ per year. It therefore represents a significant potential for achieving the objectives of "Factor 4", validated by the Grenelle Environnement in 2007, which aims to divide by 4 greenhouse gas emissions by 2050. The impact of mass transfers on the real energy behavior of buildings has been highlighted for several years [2]. The transfer equations are known, but very few works [3], [4] integrate these models in order to implement energy efficient control laws that ensure hygrothermal comfort [5] within buildings. Yet, moisture directly impacts comfort in buildings since its rate reflects both the health of buildings and the quality of indoor air. The main causes of development of moisture [6] are related to defects in HVAC systems (direct infiltration of moist air, negative pressure gradient across the envelope, inadequate ventilation, etc.) or inappropriate use of the building (high occupancy density, bad air conditioning settings, etc.).

In this paper, a complete methodology of modeling the hygrothermal behavior of a multi-zone office building is proposed. It uses the Simscape ${ }^{\mathrm{TM}}$ library in MATLAB/Simulink ${ }^{\circledR}$ environment. The application target is the "Eco-Safe" platform (CRAN Nancy, France) that fits in a global context of smart home [1].

\section{THERMAL COMFORT}

The notion of comfort is closely related to one-off adjustments in body regulation, both global and local. The perception of cold and heat depends on many parameters. However, it is possible to statistically characterize average

This work has financial support from the Contrat de Plan EtatRégion (CPER) Lorraine 2015-2020, project "Matériaux, Energie, Procédés". 978-1-5386-4291-7/18/\$31.00 @ 2018 IEEE comfort zones. If we consider a volume of air (i) (called afterwards zone (i) ) bounded by $n$ walls, the most determining parameters of atmosphere are the ambient temperature of the air $T_{(1)}$, the temperature of the $n$ walls $T_{k \oplus}(1 \leqslant k \leqslant n)$, the relative humidity of the air $\phi_{(\mathbb{1})}$ and the flow rate of air [7]. The objective of this paragraph is to specify the requirements of hygrothermal comfort in current situations (for resting persons).

\section{A. Operative temperature}

The operational temperature $T_{o(1)}$ in zone (i) is a simplified measure of human thermal comfort derived from air temperature, mean radiant temperature and air speed. When the air speed is less than $0.2 \mathrm{~m} / \mathrm{s}$, (as is typical in buildings), $T_{o(1)}$ can be approached by the arithmetic mean of air temperature in zone (i) $\left(T_{(1)}\right)$ and mean radiant temperature $T_{m r(1)}$ [7]:

$$
T_{o(1)} \approx \frac{T_{m r(1)}+T_{\oplus}}{2}
$$

where $T_{m r(1)}$ is defined by:

$$
T_{m r(1)}=\frac{\sum_{k} S_{k(1)} \times T_{k \oplus}}{\sum_{k} S_{k(1)}}
$$

A model of adaptive thermal comfort was proposed by [8] based on objective investigations carried out in buildings in situ. The model consists of a simple linear regression of the comfort temperature $T_{\text {comf }}(k)$ depending on the filtered outside air temperature:

$$
T_{\text {comf }}(k)= \begin{cases}0.049 T_{r m}(k)+9.2 & \text { if } T_{r m}(k) \leq 283.15 \\ 0.206 T_{r m}(k)-34.85 & \text { if } T_{r m}(k)>283.15\end{cases}
$$

with $T_{r m}(k)$ such that:

$$
T_{r m}(k)=0.8 T_{r m}(k-1)+0.2 T_{d m}(k-1)
$$

and $T_{d m}(k-1)$ the daily mean outdoor temperature $T_{\odot}$ on day $(k-1)$.

A first criterion of thermal comfort is to ensure that operational temperature $T_{O(1)}$ (1) belongs to the comfort temperature interval defined by $T_{\text {comf }} \pm 2 \mathrm{~K}$. Nevertheless, a source of thermal discomfort remains if the difference between the ambient temperature $T_{\odot}$ and the wall surface temperature $T_{k \text { (1) }}$ is too big. So, the comfort objectives have to include $\left|T_{\oplus}-T_{k_{(}}\right|<8 \mathrm{~K}$ for glass areas and $5 \mathrm{~K}$ for opaque walls. 


\section{B. Humidity}

Moisture may condense on surface $\left(\Sigma_{k}\right)$ bounding zone $\mathrm{i}$ when the relative humidity of the air $\phi_{(\mathbb{1})}$ is important and when the difference of temperature between $T_{\oplus}$ and that of the walls $T_{k(1)}$ is too big. $\phi_{(1)}$ depends on the vapor pressure $P_{v(1)}$ and the saturation vapor pressure $P_{v s(1)}$ in zone (i) according to the relation:

$$
\phi_{(1}(\%)=100 \frac{P_{v(1)}}{P_{v s(1)}}=100 \frac{\rho_{v(1)}}{\rho_{v s(1)}}
$$

where $\rho_{v(1)}$ and $\rho_{v s(1)}$ are respectively the densities of water vapor in zone (i) associated with vapor pressure $P_{v(1)}$ and $P_{v s(1)}$. Saturation vapor pressure $P_{v s \mathbb{1}}$, which does not decrease with the barometric pressure, corresponds to the maximum partial pressure that can reach $P_{v \oplus}$ without generating condensation. It can be estimated from Tetens' formula [7]:

$$
P_{v s(1)}=610,78 \times \exp \left(\frac{17.269\left(T_{(}-273.15\right)}{T_{\oplus}-35.85}\right)
$$

To avoid the surface condensation on wall $\left(\Sigma_{k}\right)$, it is therefore necessary that the temperature $T_{k_{(}}$be higher than the dewpoint temperature $T_{d \oplus}$ of this zone (i), which is the temperature from which the air becomes saturated with water vapor and that water condenses. For a relative humidity equal to $\phi_{\mathbb{1}}$ and an internal temperature $T_{(1)}, T_{d(1)}$ is such that:

$$
610,78 \times \exp \left(\frac{17.269\left(T_{d \oplus}-273.15\right)}{T_{d(}-35.85}\right)=\frac{\phi_{(}}{100} P_{v s(1)}
$$

In addition, just as the difference in temperature between two faces of a $\left(\Sigma_{k}\right)$ creates a heat flow, the difference in humidity revealed by the vapor pressure creates a gradient in the material and therefore a "flow" of moisture. To avoid any condensation phenomenon in the heart of the wall, it is imperative that at all points of this wall the vapor pressure is lower than the saturation vapor pressure $P_{v s k}$.

Furthermore, air quality standards recommend for France a humidity rate $\phi_{\oplus}(\%)$ between 40 and $60 \%$. So, overall, we will have to ensure in terms of humidity:

$$
\left\{\begin{array}{l}
40 \%<\phi_{\oplus}(\%)<60 \% \\
P_{v k \oplus}<P_{v s(} \Rightarrow T_{k(1)}>T_{d(1)} \\
P_{v k}<P_{v s k}
\end{array}\right.
$$

\section{HYGROTHERMAL MODELING FOR BUILDINGS}

The different models of building components are developed in this section. The approximations made are justified by taking as an example the city of Nancy (France, $\approx 230 \mathrm{~m}$ altitude).

\section{A. Moisture and heat balances into one zone}

1) Sensible heat balance: Taking into account the thermal capacity of moist air, i.e that of dry air and water vapor, the energy balance in a (i) area delimited by $n$ walls consists in

\begin{tabular}{|c|c|c|}
\hline Par. & Description & SI units \\
\hline$C_{m k}$ & Specific moisture capacity of material $\left(\Sigma_{k}\right)$ & $\mathrm{kg} /(\mathrm{kg} \cdot \mathrm{Pa})$ \\
\hline$C_{p_{d a}}$ & Specific heat capacity of dry air $(=1006)$ & $\mathrm{J} /(\mathrm{kg} \cdot \mathrm{K})$ \\
\hline$C_{p k}$ & Specific heat capacity of material $\left(\Sigma_{k}\right)$ & $\mathrm{J} /(\mathrm{kg} \cdot \mathrm{K})$ \\
\hline$C_{p_{v}}$ & $\begin{array}{l}\text { Specific heat capacity of water vapor } \\
(=1860)\end{array}$ & $\mathrm{J} /(\mathrm{kg} \cdot \mathrm{K})$ \\
\hline$h_{c}$ & $\begin{array}{l}\text { Heat transfer coefficient }(\approx 8.3 \text { (interior) } \\
\text { and } \approx 34 \text { (exterior; normal conditions) } \\
[9])\end{array}$ & $\mathrm{W} /\left(\mathrm{m}^{2} \cdot \mathrm{K}\right)$ \\
\hline$h_{m}$ & $\begin{array}{l}\text { Water vapor transfer coefficient } \\
\left.\qquad \approx 7 e^{-9} \times h_{c}\right)\end{array}$ & $\mathrm{kg} /\left(\mathrm{m}^{2} \mathrm{~s} \cdot \mathrm{Pa}\right)$ \\
\hline$h_{v}$ & $\begin{array}{l}\text { Latent heat of vaporization of water } \\
\left(=2.5 e^{6}\right)\end{array}$ & $\mathrm{J} / \mathrm{kg}$ \\
\hline$n_{a}$ & Number of moles of air per $m^{3}(\approx 41)$ & $\mathrm{mol} / \mathrm{m}^{3}$ \\
\hline$P_{d a(1)}$ & Dry air pressure of zone (i) & \\
\hline$R_{d a}$ & Gas constant for dry air $=287.1$ & $\mathrm{~J} /(\mathrm{kg} \cdot \mathrm{K})$ \\
\hline$R_{v}$ & Gas constant for water vapor $=461.5$ & $\mathrm{~J} /(\mathrm{kg} \cdot \mathrm{K})$ \\
\hline$S_{k(1)}$ & Area of surface $\left(\Sigma_{k}\right)$ in contact with zone (i) & $\mathrm{m}^{2}$ \\
\hline $\begin{array}{l}V_{(1)} \\
V_{k}\end{array}$ & $\begin{array}{l}\text { Volume of zone } \mathrm{i} \\
\text { Volume of material }\left(\Sigma_{k}\right)\end{array}$ & $\mathrm{m}^{3}$ \\
\hline$\delta_{p k}$ & $\begin{array}{l}\text { Vapor permeability of material }\left(\Sigma_{k}\right) \\
\quad\left(\frac{e_{k}}{\delta_{j k}}=R_{k} \text { is the moisture resistance) }\right.\end{array}$ & $\mathrm{kg} /(\mathrm{m} \cdot \mathrm{s} \cdot \mathrm{Pa})$ \\
\hline$\lambda_{k}$ & $\begin{array}{l}\text { Thermal conductivity of material }\left(\Sigma_{k}\right) \\
\left(\frac{e_{k}}{\lambda_{k}}=R_{k} \text { is the thermal resistance }\right)\end{array}$ & $\mathrm{W} /(\mathrm{m} \cdot \mathrm{K})$ \\
\hline$\rho_{d a(1)}$ & Density of dry air in zone (i) & $\mathrm{kg} / \mathrm{m}^{3}$ \\
\hline
\end{tabular}
equaling the sum of all incoming and outgoing heat fluxes
TABLE I

NOMENCLATURE

with the temporal variation of enthalpy $H_{\oplus}(t)$ of moist air (See table I):

$$
\begin{aligned}
& \dot{H}_{\oplus}(t)=\left(\rho_{d a \oplus 1}(t) C_{p_{d a}}+\rho_{v(1)}(t) C_{p_{v}}\right) V_{\oplus} \dot{T}_{\oplus}(t) \\
& =C_{p_{d a}} \frac{P_{d a \oplus}(t)}{R_{d a} T_{\oplus}(t)}\left(1+1.15 \frac{P_{v(1)}(t)}{P_{d a(1}(t)}\right) V_{\oplus} \dot{T}_{\oplus}(t) \\
& =\sum_{j} q_{j(1)}(t)
\end{aligned}
$$

knowing that $\rho_{d a(1)}(t)=\frac{P_{d a(1)}(t)}{R_{d a} T_{(1)}(t)}, \rho_{v(1)}(t)=\frac{P_{v(1)}(t)}{R_{v} T_{(1)}(t)}$.

This sensible heat balance is a nonlinear differential equation. However, as in general the pressure at sea level is between 980 and $1040 \mathrm{hPa}$ (usual meteorological conditions in France) and that the temperature in a (i) zone is such that $288<T_{\oplus}(t)<$ $308 \mathrm{~K}$, (9) can be approached for the city of Nancy by the following linear differential equation with a maximum error of $\pm 9 \%$ on the estimation of the term weighting $\dot{T}_{\oplus}(t)$ :

$$
1.15 \times C_{p_{d a}} V_{\oplus} \dot{T}_{\oplus}(t)=\sum_{j} q_{j \oplus}(t)
$$

2) Moisture balance: Into zone (i), the density of water vapor $\rho_{v(1}(t)$ does not vary as the temperature or pressure changes, as long as moisture is not added or removed. It follows:

$$
V_{\text {(1) }} \dot{\rho}_{v(1)}(t)=\sum_{j} g_{j(1)}(t)
$$

3) Convective transfer: Since the area (i) is assumed to be in contact with $n$ walls $\left(\Sigma_{k \oplus}\right)$, each surface side $S_{k \oplus 1}$, of interior temperature $T_{k_{(1)}}(t)$ and of water vapor density equal 
to $\rho_{v \text { (1) }}(t)$, is the place of a convective heat / moisture flow with the air of the (i) zone according to the relations [10]:

$$
\left\{\begin{array}{l}
g_{1_{(1)}}(t)=-\sum_{k=1}^{n} \frac{P_{(1)}(t)}{n_{a}} h_{m} S_{k(1)}\left(\rho_{v(1)}(t)-\rho_{v k \text { (1) }}(t)\right) \\
q_{1_{(1)}}(t)=-\sum_{k=1}^{n} h_{c} S_{k(1)}\left(T_{\text {(1) }}(t)-T_{k \text { (1) }}(t)\right)+h_{v} g_{1(1)}(t)
\end{array}\right.
$$

where $h_{m}, h_{c}, h_{v}$ and $n_{a}$ are defined in table I and $\frac{P_{(1}(t)}{n_{a}} \approx$ 2500 .

Temperatures $T_{k(1)}$ and densities of water vapor $\rho_{v k(1)}(t)$ in relation (12) can be determined by means of moisture and heat balances in walls surrounding zone (i).

\section{B. Moisture and heat balances in walls / windows}

Let us consider a homogeneous and isotropic material $\left(\Sigma_{k}\right)$ of thickness $e_{k}$ delimited by two parallel surfaces $\left(\Sigma_{k(1)}\right)$ and $\left(\Sigma_{k \uparrow}\right)$, this environment being able to represent for example a wall, a window, a door, etc. It is assumed that the temperature and the partial pressure of water vapor are identical at every point of each surface (one-dimensional conduction through the material). Let $\left(T_{k_{(1)}}(t), P_{v k_{\text {(1) }}}(t), \rho_{v k_{\text {(1) }}}(t)\right)$ and $\left(T_{k \oplus}(t), P_{v k \oplus}(t), \rho_{v k \Phi}(t)\right)$ be the temperature, the partial vapor pressure and the vapor density characterizing each of the two surfaces $\left(\Sigma_{k \text { (1) }}\right)$ and $\left(\Sigma_{k \text { (1) }}\right)$ respectively. It follows from this hypothesis that the mass and thermal flows are carried out perpendicularly to these surfaces. The remainder of this section presents the mass and sensible heat balances performed on the equidistant central surface of $e_{k} / 2$ of $\left(\Sigma_{k \text { (1) }}\right)$ and $\left(\Sigma_{k(1)}\right)$. Let $T_{k}(t), P_{v k}(t)$ and $\rho_{v k}(t)$ be the temperature, the vapor pressure and the density of vapor in $\left(\Sigma_{k}\right)$. The model of the coupled heat and moisture transport is based on the well-known laws of Fourier, Fick and Darcy.

1) Moisture balance: In porous unsaturated materials, moisture transfer occurs in two forms: liquid and water vapor. The transfer of liquid water is induced by a capillary pressure gradient but is not considered in this work (building supposed healthy). The transport of water vapor is a diffusional process under a vapor pressure gradient, governed by Fick's law $\left(\frac{g_{v}}{S_{k}}=-\delta_{p k} \operatorname{grad}\left(P_{v}\right)\right)$. The mass balance at $\left(\Sigma_{k}\right)$ is given by (See table I):

$$
V_{k} \dot{\rho}_{v k}(t)=\frac{-2 S_{k}}{\rho_{k} C_{m k}} \times \sum_{(\mathbb{1}=(1),(1)} \frac{\delta_{p k}}{e_{k}}\left(\rho_{v k}(t)-\rho_{v k \Phi}(t)\right)
$$

with:

$$
\left\{\begin{array}{l}
\rho_{v k}(t)=\rho_{k} C_{m k} P_{v k}(t) \\
\rho_{v k \oplus}(t)=\rho_{k} C_{m k} P_{v k \oplus}(t)
\end{array}\right.
$$

2) Heat balance: The transfer of heat in the porous environment occurs under three forms : a flow of conduction under a gradient of temperature expressed by the law of Fourier $\left(\frac{q_{\text {cond }}}{S_{k}}=-\lambda \operatorname{grad}(T)\right)$, an advection of sensitive heat through the flows of liquid and steam (classically neglected [11]) and a transfer of latent heat of change of phase driven by the steam $\left(\frac{q_{v}}{S_{k}}=-h_{v} \delta_{p k} \operatorname{grad}\left(P_{v}\right)\right)$. The balance equation of the energy conservation is (See table I):

$$
\begin{aligned}
\rho_{k} C_{p k} V_{k} \dot{T}_{k}(t) & =-2 S_{k} \times \sum_{\text {(1) }=\text { (1),(1) }} \frac{\lambda_{k}}{e_{k}}\left(T_{k}(t)-T_{k \oplus 1}(t)\right) \\
- & \frac{2 S_{k} \sigma h_{v}}{\rho_{k} C_{m k}} \times \sum_{\text {(1) }=\text { (1) },(\mathbb{1})} \frac{\delta_{p k}}{e_{k}}\left(\rho_{v k}(t)-\rho_{v k \text { (1) }}(t)\right)
\end{aligned}
$$

Remark 1: For a wall $\left(\Sigma_{k}\right)$, if the Biot numbers defined for the transfers of heat and transfer of mass respectively by:

$$
B i=\frac{h_{c} e_{k}}{\lambda_{k}} ; \quad B i_{m}=\frac{h_{m} e_{k}}{\delta_{p k}}
$$

are small in front of $1\left(B i<0.1\right.$ and $B i_{m}<0.1$ by considering the coefficients $h_{c}$ and $h_{m}$ for both surfaces $\left(\Sigma_{k \text { (1) }}\right)$ and $\left.\left(\Sigma_{k(1)}\right)\right)$ then the resistance to conduction within $\left(\Sigma_{k}\right)$ is much lower than the resistance to convection across the air boundary layer. In this case, the assumption of uniform temperature/partial vapor distribution in $\left(\Sigma_{k}\right)$ is reasonable and Equations (15) and (13) become $\left\{\begin{array}{l}\rho_{v k}(t)=\rho_{v k \text { (1) }}(t)=\rho_{v k \text { (1) }}(t) \\ T_{k}(t)=T_{k \text { (1) }}(t)=T_{k \text { (1) }}(t)\end{array}\right.$

\section{Mass and heat exchanges within a zone}

1) linked to the air movements: We consider air exchange and denote in $\mathrm{m}^{3} / \mathrm{s}$ the effective flow rate of outdoor air, including infiltration and mechanical ventilation. Assuming that the air is renewed from outside at a temperature $T_{\odot}(t)$ due to a constant flow $Q_{a}$, a mass algebraic flow $g_{2 \text { (1) }}(t) /$ heat $q_{2 \text { (1) }}(t)$ exists and is defined by:

$$
\left\{\begin{array}{l}
g_{2(1)}(t)=-Q_{a}\left(\rho_{v(1)}(t)-\rho_{v \odot}(t)\right) \\
q_{2(1)}(t)=-1.15 \times Q_{a} C_{p_{d a}}\left(T_{(1)}(t)-T_{\odot}(t)\right)
\end{array}\right.
$$

Let us assume that a CMV is used to circulate the air between rooms (i) and (i). It is assumed that the air taken in the 'source' room is replaced by the outside air through the openings at the level of the windows. On the other hand, air received by the 'destination' room replaces a part of its air that is equally displaced through the openings at the level of the windows. Two air masses of different psychrometric characteristics are thus mixed. Let $\left(\rho_{v \text { (1) }}, T_{(1)}\right)\left(t_{o n}\right)$ and $\left(\rho_{v(1)}, T_{(1)}\right)\left(t_{o n}\right)$ be these characteristics within each zone (i) and (j) at the moment $t_{\text {on }}$ the CMV is switched on. If we take the example that the air goes from zone (i) to zone (i), the humidity / heat balance is:

$$
\left\{\begin{array}{l}
g_{3 \oplus}(t)=-Q_{c m v}\left(\rho_{v(1)}(t)-\rho_{v(1)}(t)\right) \\
q_{3 \oplus}(t)=-1.15 \times Q_{c m v} C_{p_{d a}}\left(T_{\oplus}(t)-T_{(1)}(t)\right)
\end{array}\right.
$$




$$
\left\{\begin{array}{l}
g_{3(1)}(t)=-Q_{c m v}\left(\rho_{v \oplus}(t)-\rho_{v \odot}(t)\right) \\
q_{3(1)}(t)=-1.15 \times Q_{c m v} C_{p_{d a}}\left(T_{\oplus}(t)-T_{\odot}(t)\right)
\end{array}\right.
$$

with $Q_{c m v}$ the air flow of the $\mathrm{CMV}$ in $\mathrm{m}^{3} / \mathrm{s}$.

2) linked to heating/cooling systems and air conditioning: Air treatment systems in buildings do not just cool/heat but also treat, filter and humidify indoor air. In this paper, we assume that the temperature $T_{h}, T_{c}$ (in $\mathrm{K}$ ) and the vapor density $\rho_{v, h}, \rho_{v, c}$ of the forced-air (in $\mathrm{kg} / \mathrm{m}^{3}$ ) in heating / cooling mode are known. The focus is on reversible heat pumps (HP). A heat pump is a thermodynamic device that allows capturing heat from outdoor air and transmitting it inside the building. If it is reversible, the HP is capable of providing air conditioning in the summer. Essentially, and without taking into account the transitional aspects, the equation translating this energy flow in zone (i) is in heating / cooling mode:

$$
\left\{\begin{array}{l}
g_{4 \oplus}(t)=-Q_{H P}\left(\rho_{v \oplus}(t)-\rho_{v, h / c}(t)\right) \\
q_{4 \oplus}(t)=-1.15 \times Q_{H P} C_{p_{d a}}\left(T_{\oplus}(t)-T_{h / c}\right)
\end{array}\right.
$$

with $Q_{H P}$ the air flow of the $\mathrm{HP}$ in $\mathrm{m}^{3} / \mathrm{s}$.

3) linked to occupancy: Table II specifies the energy and the water vapor released by one person depending on his activity and the temperature of zone (i).

TABLE II

\begin{tabular}{|c|c|c|c|c|c|c|}
\hline \multirow{2}{*}{$\begin{array}{l} \\
T_{(1)} \\
\text { (C) }\end{array}$} & \multicolumn{2}{|c|}{$\begin{array}{c}\text { Rest to } \\
\text { light activity }\end{array}$} & \multicolumn{2}{|c|}{$\begin{array}{l}\text { Light to sustai- } \\
\text { ned activity }\end{array}$} & \multicolumn{2}{|c|}{$\begin{array}{c}\text { Heavy } \\
\text { physical activity }\end{array}$} \\
\hline & $\begin{array}{l}g_{5(1)} \\
(\mathrm{g} / \mathrm{h})\end{array}$ & $\begin{array}{l}q_{5 \text { (1) }} \\
(\mathrm{W})\end{array}$ & $\begin{array}{l}g_{5 \text { (1) }} \\
(\mathrm{g} / \mathrm{h})\end{array}$ & $\begin{array}{l}q_{5 \text { (1) }} \\
\text { (W) }\end{array}$ & $\begin{array}{l}g_{5(1)} \\
(\mathrm{g} / \mathrm{h})\end{array}$ & $\begin{array}{l}q_{5 \text { (1) }} \\
(\mathrm{W})\end{array}$ \\
\hline 18 & 35 & 125 & 95 & 190 & 165 & 270 \\
\hline 21 & 35 & 120 & 110 & 190 & 185 & 270 \\
\hline 22 & 40 & 120 & 125 & 190 & 215 & 270 \\
\hline 23 & 50 & 120 & 135 & 190 & 225 & 270 \\
\hline 24 & 60 & 115 & 140 & 190 & 230 & 270 \\
\hline 25 & 60 & 115 & 145 & 190 & 240 & 270 \\
\hline 26 & 65 & 115 & 150 & 190 & 250 & 270 \\
\hline
\end{tabular}

HEAT/MOISTURE FLUX

4) linked to the absorbed shortwave solar radiations: The sun provides heat that greatly influences the temperature within the platform rooms. To estimate the solar energy transmitted, it is necessary to follow the positioning of the sun and to take into account direct solar and diffuse radiation. In order to understand the calculations to quantify the global radiation, it is important to define not only the various solar components, but also the different angles used for calculations [12]. These angles are the local latitude $(\Phi)$, the hour angle $(\omega)$ in the local solar time, the solar declination $\left(\delta_{s}\right)$ and the solar azimuth $\left(\phi_{s}\right)$. The energy related to direct solar radiation is such that:

$$
\begin{aligned}
& q_{6 \oplus}(t)=1260 S_{w k} \exp \left(\frac{-1}{2.3\left(\alpha_{s}(t)+3\right) \sin \left(\alpha_{s}(t)\right)}\right) \\
& \times \cos (\beta(t))
\end{aligned}
$$

where $S_{w k}$ is the surface of the windows of $\left(\Sigma_{k}\right), \alpha_{s}(t)$ is the solar elevation angle and $\beta(t)$ is the angle of incidence

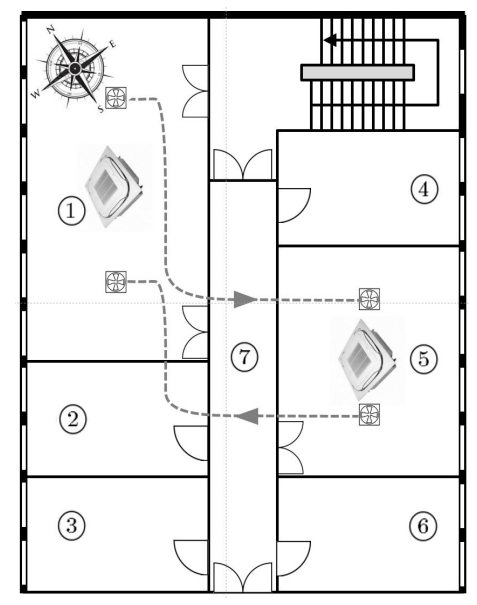

Fig. 1. The "Eco-Safe" platform.

between the suns rays and the face of windows. As for the diffused radiation energy, it is calculated by the relationship:

$$
\begin{aligned}
q_{7 \text { (1) }}(t)=S_{w k} & \left(62.5 \times(1+\cos (i)) \sin \left(\alpha_{s}(t)^{0.4}\right)\right. \\
+ & \left.+108 \times(1-\cos (i)) \sin \left(\alpha_{s}(t)^{1.22}\right)\right)
\end{aligned}
$$

\section{HYGROTHERMAL MODELING BY NODAL METHOD - APPLICATION TO THE "ECO-SAFE" PLATFORM}

By this type of approach, each node represents volumes of material or components, while inter-node connections represent the flow paths of thermal and mass fluxes (walls, doors, windows, etc.) [1], [13]. The graphic representation of the model has the same appearance as an electrical diagram, hence the analogue method name where:

- the temperature and density of water vapour are represented by electrical potentials;

- energy flows and mass transfers are represented by current intensities;

- thermal and moisture resistances are represented by electrical resistances;

- the thermal and moisture retention capacities are represented by capacitors.

For example illustration, the "Eco-Safe" platform shown in Figure 1 is considered. The electrical circuits translating the energy and mass models within this platform are represented at the top of Figure 2. For each zone, a global model is defined by assembling the different hygrothermal blocks. It consists of four walls, a double glazed window, a floor and a ceiling. The model of this part is illustrated for room (1) at the bottom right corner of Figure 2. The consideration of heterogeneous walls (e.g. window and wall) result in as many circuits $R C$ paralleled. An example of a wall model considering a window with double glazing is represented at the bottom left corner of Figure 2. For the sake of simplicity and due to the low impact of term $h_{v} g_{1 \text { (1) }}(t)$ in (12) during winter conditions, the latter has been neglected. 


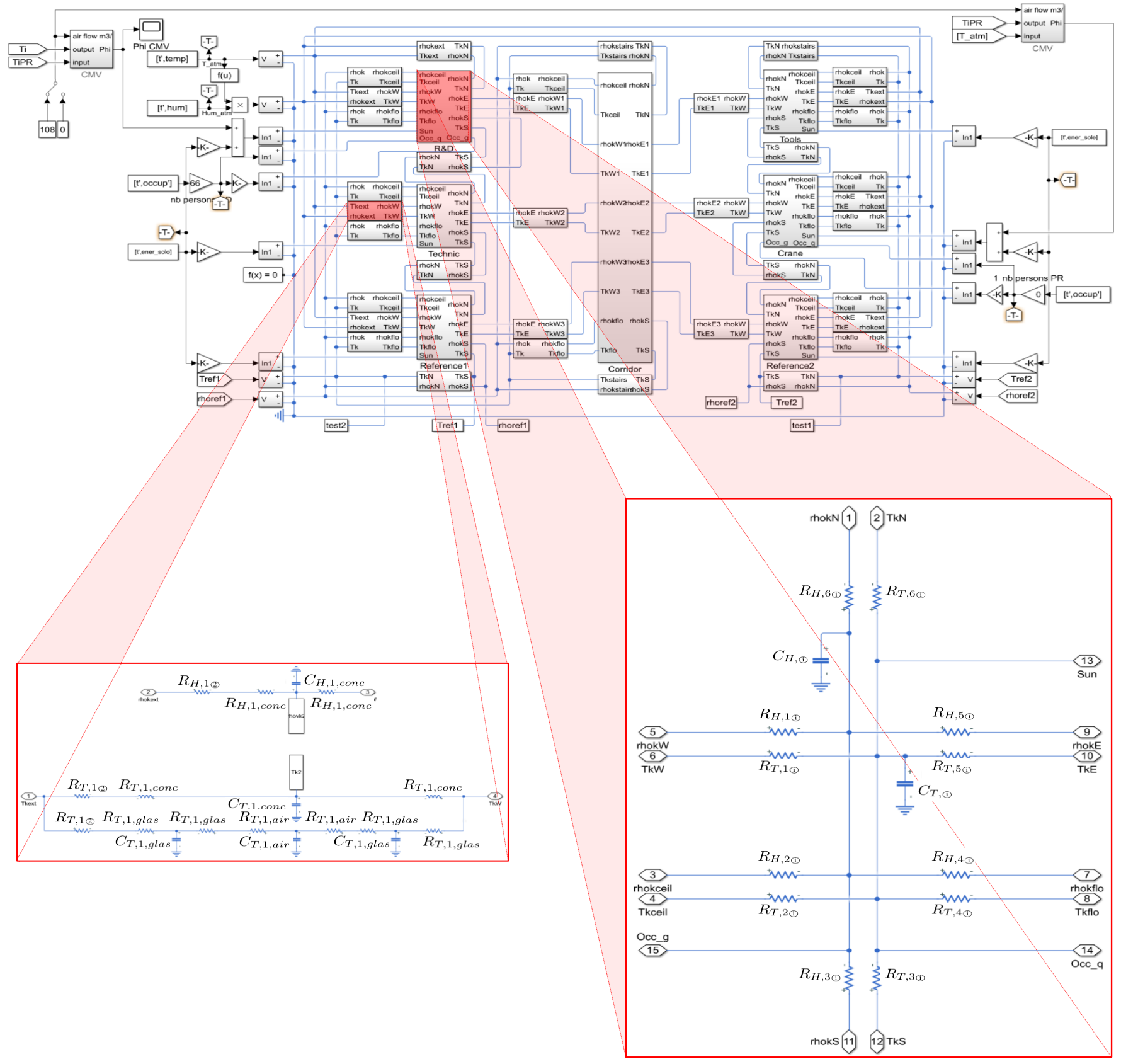

Fig. 2. Hygrothermal modeling of "Eco-Safe" platform.

Parameters $R$ and $C$ of the simulator were determined from the nature and characteristics of the different materials used in the wall dividers, walls and windows of the platform. They have been initialized taking into account theoretical values of certain parameters specified in table III and according to the following analogies:

- for zone (i):

$$
\left\{\begin{array}{l}
R_{T, k \oplus}=\frac{1}{h_{c} S_{k(1}} \\
R_{H, k \oplus}=\frac{1}{2500 h_{m} S_{k(1)}}
\end{array} ;\left\{\begin{array}{l}
C_{T,(1)}=1.15 C_{p_{d a}} V_{(1)} \\
C_{H,(1)}=V_{(1)}
\end{array}\right.\right.
$$

- for wall / windows / ceil / floor $k$ :

$$
\left\{\begin{array}{l}
R_{T, k}=\frac{e_{k}}{2 \lambda_{k}} \\
R_{H, k}=\frac{e_{k}}{2 \delta_{k}}
\end{array} ;\left\{\begin{array}{l}
C_{T, k}=\rho_{k} C_{p k} e_{k} \\
C_{H, k}=\rho_{k} C_{m k} e_{k}
\end{array}\right.\right.
$$

They have been adjusted from the temperature curves actually observed on the system. According to figures 3 and 4, it appears that the profiles of actual and estimated temperature values are found to be similar. The simulated curves were generated from the entries $T_{\odot}(t)$ and $\rho_{v \odot}(t)$ (Figure 5), which are the data issued from the weather station over the period 3/5/2018 - 3/9/2018. 
TABLE III

THEORETICAL VALUES OF HYGROTHERMAL PARAMETERS [14]

\begin{tabular}{c|cccc} 
& $\rho_{k}$ & $\delta_{p k}\left(e^{-12}\right)$ & $C_{p k}$ & $\lambda_{k}$ \\
\hline Concrete & 2400 & 1.4 & 1000 & 2 \\
Air & 1.23 & 185 & 1006 & 0.025 \\
Polystyrene & 40 & 3.1 & 1450 & 0.04 \\
Glass & 2580 & 0 & 720 & 1.2 \\
\hline
\end{tabular}

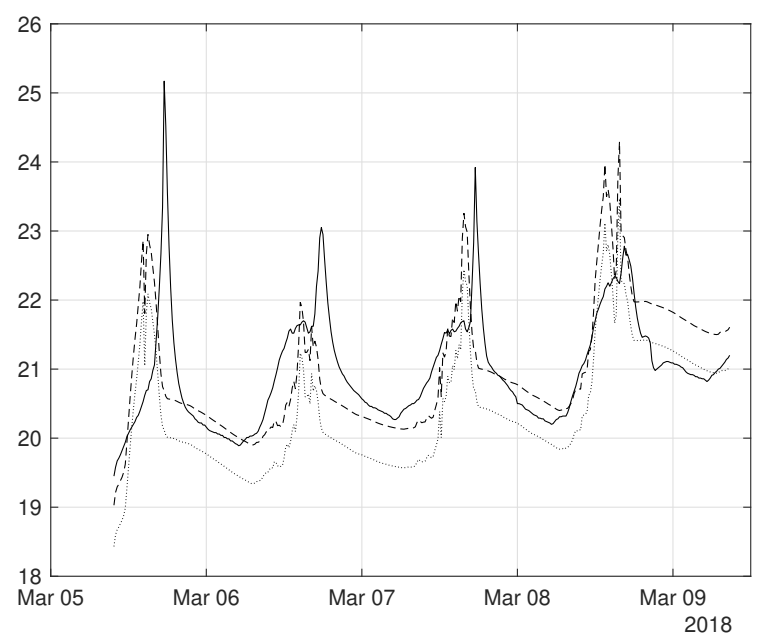

Fig. 3. Measured (solid line) and estimated (dashed line) temperatures for zoom (1). An estimation of the operative temperature is represented in dotted line.

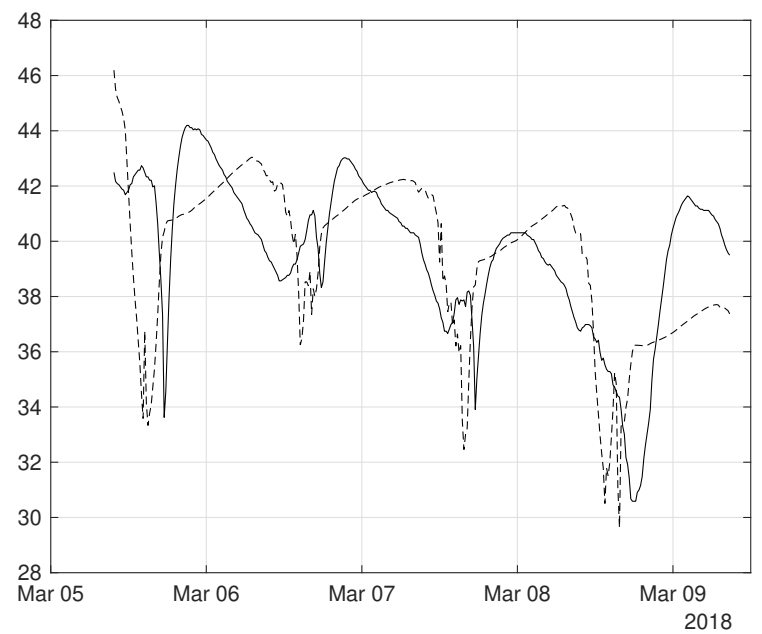

Fig. 4. Measured (solid line) and estimated (dashed line) humidity rates in zone (1).

\section{CONClusion}

In this paper, a complete methodology has been established for modeling the hygrothermal behavior of a multi-zone office building. The application target is the "Eco-Safe" platform (CRAN Nancy, France). This study takes into account not only all the walls/windows and equipments (CMV, heat pump) fitted to each of the zones but also the effects of solar radiations and occupants. In a practical context, in order to facilitate the determination of a hygrothermal model of a multi-zone

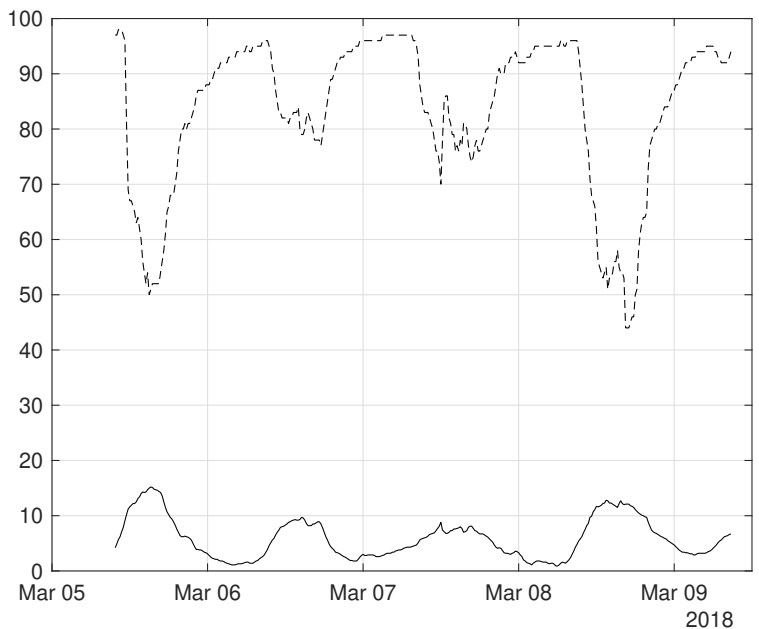

Fig. 5. Outside temperature (solid line) and humidity rate (dashed line) of outdoor air $(3 / 5 / 2018$ - 3/9/2018).

building, the proposed nodal method is based on the use of the thermal electric analogy. In perspectives, it would be interesting to implement an efficient control law based on this model.

\section{REFERENCES}

[1] F. Gabsi, F. Hamelin, R. Pannequin, and M. Chaabane, "Energy efficiency of a multizone office building: MPC-based control and simscape modelling," in Proceedings of the 6th International Conference on Smart Cities and Green ICT Systems - Volume 1: SMARTGREENS. Porto, Portugal: INSTICC, April 2017, pp. 227-234.

[2] M. Woloszyn and C. Rode, "Tools for performance simulation of heat, air and moisture conditions of whole buildings," Building Simulation, vol. 1, no. 1, pp. 5-24, Mar 2008

[3] R. H. Peuhkuri, "Moisture dynamics in building envelopes," Ph.D. dissertation, Technical University of Denmark, Copenhagen, Denmark, 102003.

[4] J. Xu and D. Nikovski, "A humidity integrated building thermal model," in 2016 American Control Conference (ACC), July 2016, pp. 1492-1499.

[5] N. Djongyang, R. Tchinda, and D. Njomo, "Thermal comfort: A review paper," Renewable and Sustainable Energy Reviews, vol. 14, no. 9, pp. $2626-2640,2010$.

[6] H. Moon and G. Augenbroe, "Evaluation of hygrothermal models for mold growth avoidance prediction," in Eighth International IBPSA Conference, Eindhoven, Netherlands, August 2003.

[7] ANSI/ASHRAE Standard 55, Thermal Environmental Conditions for Human Occupancy. Atlanta, Georgia: ASHRAE, 2013.

[8] K. J. McCartney and J. F. Nicol, "Developing an adaptive control algorithm for europe," Energy and Buildings, vol. 34, no. 6, pp. 623 - 635, 2002, special Issue on Thermal Comfort Standards.

[9] N. Hutcheon and G. Handegord, Building science for a cold climate. Wiley, 1983.

[10] R. L. Webb, "Standard nomenclature for mass transfer processes," International Communications in Heat and Mass Transfer, vol. 17, no. 5, pp. $529-535,1990$.

[11] D. A. De Vries, "Simultaneous transfer of heat and moisture in porous media," Eos, Transactions American Geophysical Union, vol. 39, no. 5, pp. 909-916, 1958.

[12] P. Calow, Blackwell's concise encyclopedia of environmental management. Blackwell Science, 1999.

[13] H. Boyer, J. Chabriat, B. Grondin-Perez, C. Tourrand, and J. Brau, "Thermal building simulation and computer generation of nodal models," Building and Environment, vol. 31, no. 3, pp. 207 - 214, 1996.

[14] British Standards Institute Staff, Building Materials and Products. Hygrothermal Properties. Tabulated Design Values, ser. B.S. (Series). British Standards Institution, 2000. 